\title{
Support for same-sex marriage after the Pulse nightclub shooting: Evidence from a quasi-experiment
}

\author{
Jack Thompson*
}

August 27, 2021

\begin{abstract}
Multiple studies find that exposure to news about mass shootings does little to increase public support for gun control. But are mass shootings able to shape public support for other policy preferences? In this paper, I conduct an empirical test of the effect of quasi-random exposure to news about the Pulse nightclub shooting - a mass shooting that occurred at an LGBTQ nightclub in Orlando, FL in June 2016 - on public support for same-sex marriage. Leveraging data from Wave 55 of The American Panel Survey (TAPS), I find that quasi-random exposure to news about the shooting increased public support for same sex-marriage by 10 points. Subgroup analyses indicate that the largest increases in support for same-sex marriage were among moderates, liberals and White Americans, while minimal increases in support were detected among conservatives and Hispanic Americans. The findings indicate that mass shootings may shape public support for policies that are related to victim characteristics such as sexual and gender identity, even if they do not shape broader support for gun control.
\end{abstract}

Keywords: Same-sex marriage; LGBTQ; Pulse nightclub; mass shootings; gun control

*Postdoctoral Research Fellow, University of Exeter. Email: j.thompson4@exeter.ac.uk 


\section{Introduction}

On June 12, 2016, 49 clubgoers were killed at Pulse, an LGBTQ+ nightclub, in Orlando FL. In addition to being one of the deadliest mass-shootings in US history, the Pulse nightclub shooting remains the deadliest instance of violence against individuals with LGBTQ+ identities in America. Scholars have long found that changes in public opinion are related to major events (Page \& Shaprio 2010). A substantial body of research has examined the effects of mass shootings on public support for gun control, finding mixed results. For instance, mass shootings may increase public support for gun control, but only in the areas that are the most geographically proximate to the sites of mass shooting themselves (Newman \& Hartman 2019). Elsewhere, however, scholars have found that shootings such as Sandy Hook in 2012 failed to increase public support for gun control, even among groups (for instance, Democrats) who are thought to be generally more supportive of tighter regulation of firearms (Rogowski \& Tucker 2019).

While the scholarship has tended to focus on public support for gun control in the wake of mass shootings, comparatively little attention has been paid as to whether these events are able to shape public support for policies related to the victim characteristics of mass shootings, even if those policies themselves are tangentially related to broader support for gun control. In the case of the Pulse nightclub shooting, there is a therefore possibility that exposure to news about the shooting shaped support for pro-LGBTQI+ policies (for instance, same sex marriage) given that many of the victims were LGBTQI+. In this research note, I therefore test for the possibility that exposure to news about Pulse led to increased support for same-sex marriage among the American public.

Like gun control, public support for same-sex marriage is conditional on a variety of factors, including sociopolitical attitudes, and demographic characters such as age, education, and religion (Lee \& Mutz 2019, Olson, Cadge \& Harrison 2006). Generally speaking, younger, well-educated, and secular Americans are among the most likely to support same-sex marriage, while older, less educated, and religious Americans are the 
least likely to exhibit support. If public support for same-sex marriage did increase after Pulse, de minimis, then we should expect to observe a significant effect on support through quasi-random assignment to the post-shooting condition, and for these effects to hold while adjusting on a vector of covariates that are already known to shape public opinion towards same-sex marriage (H1). Notwithstanding, there is reason to expect that any general trends in public support for same-sex marriage mask noteworthy responses to treatment assignment when individuals are contrasted on their sociopolitical attitudes. Given the extent of sociopolitical sorting and issue polarization (Mason 2015), there are likely to be asymmetric reactions to "as if" random assignment to the treatment condition when individuals are contrasted on ideology (H2). Finally, the Pulse nightclub shooting also deeply affected the Latino community in Orlando, with more than 90 percent of victims being of Hispanic or Latino origin (Madigan et al.|2016). If Hispanic Americans were likely to have been aware of the shooting at the time it occurred, this raises the possibility that public support for same-sex marriage increased more precipitously among Hispanics relative to non-Hispanic individuals, given the shared ethnoracial identities of many of the victims (H3).

To test these expectations, I present quasi-experimental evidence from Wave 55 of The American Panel Survey (TAPS), conducted between June 8 and July 8, 2016. Exploiting "as if" random exposure to news about the Pulse nightclub shooting, I rely on the "unexpected event during survey fieldwork" study design (Muñoz et al. 2020) to provide evidence that respondents quasi-randomly assigned to the post-shooting condition exhibited higher levels of support for same sex marriage than those in the pre-shooting condition.

This research note provides two important contributions to the extant scholarship. First, it provides quasi-experimental evidence that mass shootings are able to shape public support for policies that are related to victim characteristics (for instance, sexual and gender identity), even if they do not shape broader public support for gun control (Ro- 
gowski \& Tucker 2019). Second, it expands the scholarship on public opinion towards LGBT rights by demonstrating that support for pro-LGBT policies can be shaped by salient events beyond exposure to news about Supreme Court cases on LGBT rights (Flores \& Barclay 2016, Kazyak \& Stange 2018).

\section{Data and Methods}

\subsection{Data}

Data are taken from Wave 55 of Washington University in St. Louis/Weidenbaum Center's The American Panel Survey (TAPS). TAPS is a nationally-representative, monthly online panel on US adults (Weidenbaum Center 2021). TAPS respondents were recruited based on a sample of addresses drawn from the US Postal Service's computerized delivery file sequence (CDFS). CDFS covers $97 \%$ of all physical addresses in the 50 states, including PO poxes and rural route addresses. Altogether, $\mathrm{N}=1,673$ respondents took part in Wave 55, which was conducted between June 8 and July 8, 2016.

\subsection{Research Design}

To assess whether exposure to news about the Pulse nightclub shooting led to increased public support for same-sex marriage, I utilize the "unexpected event during survey fieldwork" study design (Muñoz et al. 2020). The Pulse nightclub shooting took place on June 12, 2016, thus occurring during survey fieldwork of Wave 55 of TAPS. This results in a sample where some TAPS respondents were likely to have been exposed to news about Pulse, while others were not. The respondents who took part in the survey before the shooting are "as if" randomly assigned to the control group (pre-shooting condition), while those who completed the survey afterward are "as if" randomly assigned to the treatment group (post-shooting condition). Thus, I am able to compare levels of support 
for same sex marriage among respondents who completed the survey before and after the shooting, and identify local causal effects related to event exposure.

In event study designs, the extent to which respondents actually absorb treatment (ignorability assumption) is a cause for concern (Muñoz et al. 2020). In the context of the current study, an insignificant effect through quasi-random exposure to news about Pulse may be a function of the horizon of my temporal bandwidth. If I specify a bandwidth that is too wide, for instance, there is a concern that respondents simply forgot the impact of the shooting when the answering the survey in the days following the event. In section A1 of the SI file, I demonstrate that halving the time of post-event exposure does not substantively alter the results presented here, where my bandwidth compromises the full duration of survey fieldwork for Wave 55.

Another concern related to violability of ignorability assumption is respondent attentiveness (Muñoz et al. 2020). In survey experiments, political scientists are increasingly utilizing attention checks to ensure that respondents actually paying attention to the surveys they take (Kane \& Barabas 2019). While Wave 55 of the APS does not an item assessing respondent attentiveness, the survey does contain a variable that measures how many minutes it took a respondent to complete the survey. In Wave 55, the minimum time it took to complete the survey was just three minutes, which, for a 150+ question survey, is far too short a time to provide considerate answers. Furthermore, the maximum time for completion is 34,586 minutes. This raises the very likely possibility that respondents went to do other things while keeping the webpage for the survey open. To address concerns related to attentiveness, models are estimated using a sample of APS respondents who completed the survey in a "reasonable duration' of time, defined as those who took between 15 and 60 minutes to complete.

To further assess the plausibility of the ignorability assumption, it is necessary to analyze the degree of covariate balance between the treatment and control groups (Muñoz et al. 2020). If imbalances appear my outcome of interest, this might lead to a statisti- 
cal dependence between assignment to treatment and the average level of support for same-sex marriage.$^{1}$ To address this concern, I utilize an entropy balancing estimator to maximize covariate balance across the treatment and control groups (Hainmueller 2012) 2 Overall, the entropy balancer performs extremely well in balancing my set of covariates. Full covariate adjustment statistics are presented in section A3 of the SI file.

Finally, another important assumption of the "unexpected event" study design is that the event itself is salient and is one that post-event survey takers were likely to have been aware of. To gauge the level of public interest in the Pulse nightclub shooting and LGBT issues around the time of June 12, I turn to Google Trends data for the U.S Figure 1 depicts levels of popular interest in "Pulse nightclub" and "LGBT" between June 1, 2016, and July 1, 2016. As indicated here, both of these terms saw a significant spike in interest after June 12. These trends thus point to the Pulse nightclub shooting being a significant event in the American public psyche at the time it occurred and demonstrates the salience of LGBT issues after it occurred (Mellon|2014).

\subsection{Dependent Measure}

The dependent measure is an item that asks respondents whether they generally support or oppose same-sex marriage. Possible responses to the item were $1=$ "yes" (44.56\%), 2 $=$ "no" (43.20\%), and $3=$ "no opinion" (12.22\%). For ease of interpretation, I dichotomize respondents to those who support same-sex marriage (1), and those who do not support same-sex marriage or have no opinion (0).

\footnotetext{
${ }^{1}$ Significant mean differences between treatment and control groups were detected on several covariates. Full balance statistics presented in section A2 of the SI file.

${ }^{2}$ Entropy balancing is a multivariate reweighting method that reweights the Nationscape dataset such that covariate distributions in the reweighted data satisfy a set of specified moment conditions. The estimator is thus useful in creating balanced samples in studies such as mine with a dichotomous treatment, where the control group data are ideally balanced to match the covariate moments in the treatment group.

${ }^{3}$ Google Trends normalizes search data to make comparisons between search parameters more understandable. In the context of the current study, search results are normalized to the time (June 1, 2016 - July 1, 2016) and location (United States). Each data point is first divided by the total searches of the geography and time range it represents to compare relative popularity. Afterward, the data are then scaled on a range of 0 to 100 based on each topics proportion to all searches on all topics.
} 
Figure 1: Popular Interest in "Pulse nightclub" and "LGBT"

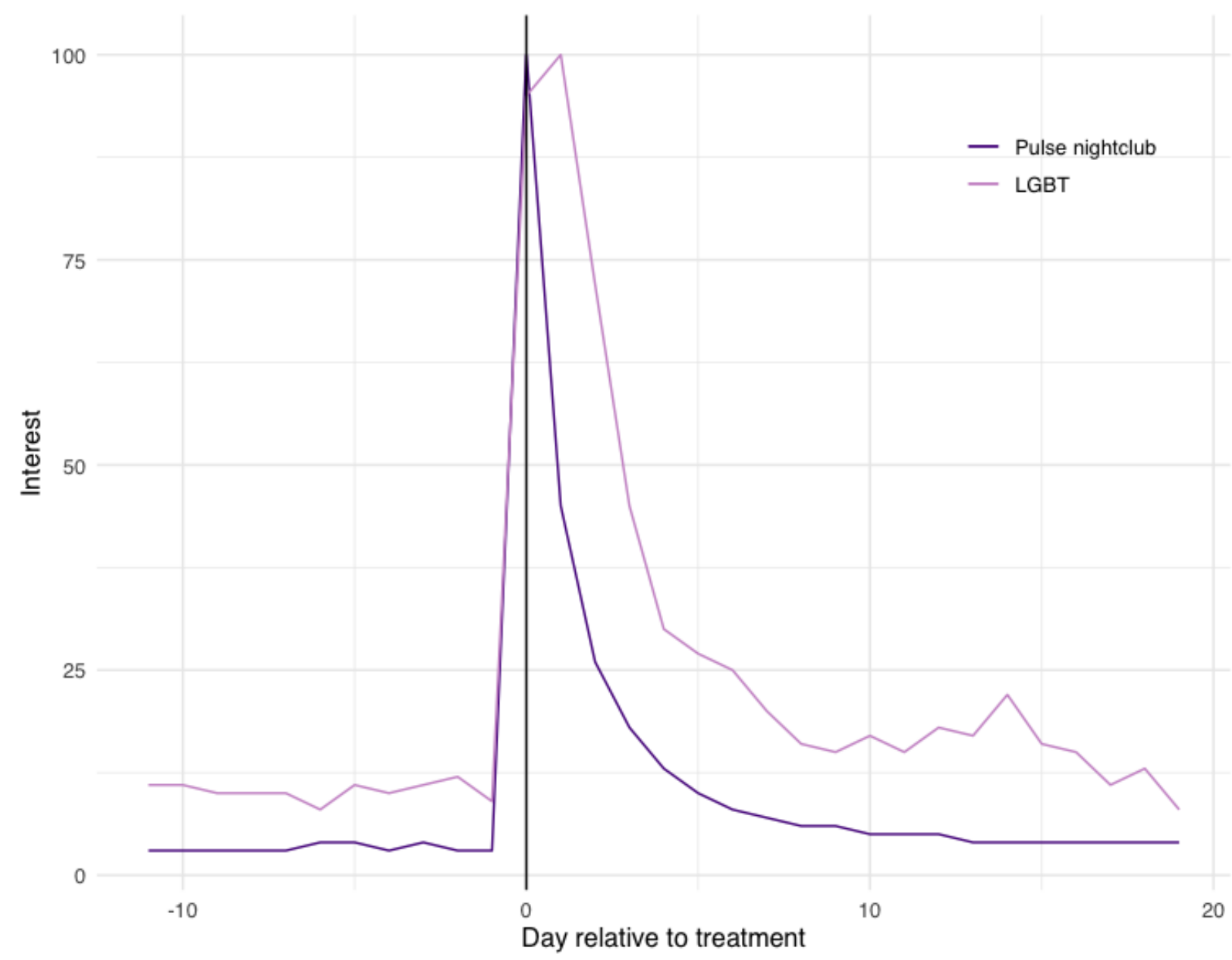

Notes: Lines represent the level of interest in "Pulse nightclub" and "LGBT," as search terms on Google between June 1, 2016 and July 1, 2016. Day of the shooting, (June 12) indicated by the vertical black line. Limited to searches made in the US.

\subsection{Treatment}

Treatment assignment is operationalized using a dichotomous measure that codes respondents surveyed before 2:02 am EST, June 12, 2016 as 0 (control group), and those afterward as 1 (treatment group) $!^{4}$

\footnotetext{
${ }^{4}$ Some cross-sectional surveys contain a time variable indicating when a respondent completed the survey. The American Panel Survey contains a precise finish time (to the second) for each respondent, allowing me to determine the appropriate cutoff point in order to maximize the likelihood of event exposure. Since that the shooting is known to have started at 2:02am, ET (Aisch et al. 2016), I use this official time as my cut-off point. Because the TAPS dataset codes respondent finish times using Greenwich Mean Time (GMT, $+0: 00$ ) as opposed to Eastern Standard Time (EST, -4:00), respondents who finished the survey before 6am GMT are coded as 0 , and those who finished the survey afterward as 1.
} 


\subsection{Covariates}

The effect of the treatment on support for same-sex marriage is adjusted while controlling for news interest (7-point ordinal item ranging between $1=$ "never," $7=$ "every day"), ideology (7-point ordinal item ranging between 1 = "very conservative," to 7 = "very liberal"), race (categorical item where 2 = "Black, non-Hispanic," $3=$ "Hispanic," $4=$ "mixed-race, non-Hispanic," 5 = "other-race, non-Hispanic," with “White, non-Hispanic" serving as the base category), age (in years), gender (females coded as 1 and males as 0), education (4-point ordinal item ranging between 1 - "less than high school," to $4=$ "bachelor's degree or higher"), and religiosity (nonreligious coded as 1, and the religious as 0$)$.

\subsection{Model}

My key term of interest is the intent to treat (ITT) effect of the quasi-random assignment to the treatment condition. The model specification is summarized in the basic model in which $\beta_{1}$ is the covariate adjusted intent to treat effect, $\left.y_{(} X^{i}\right)$ is a vector of individual covariates (news interest, ideology, race, age, gender, education, and religion), and $\epsilon_{i}$ is the error term:

$$
\left.Y_{i}=a+\beta_{1}+y_{(} X^{i}\right)+\epsilon_{i}
$$

Given that my outcome measure of interest is dichotomous, models are estimated using logit 5

\section{Results}

I begin by presenting the results of my model estimating the effect of quasi-random exposure to news about the Pulse nightclub shooting on support for same-sex marriage

\footnotetext{
${ }^{5}$ Replications using an ordered logit estimator do not substantively alter the significance and direction of the results presented in the main paper (see section A5 of the SI file).
} 
Figure 2: Modelling Who Supports Same-Sex Marriage

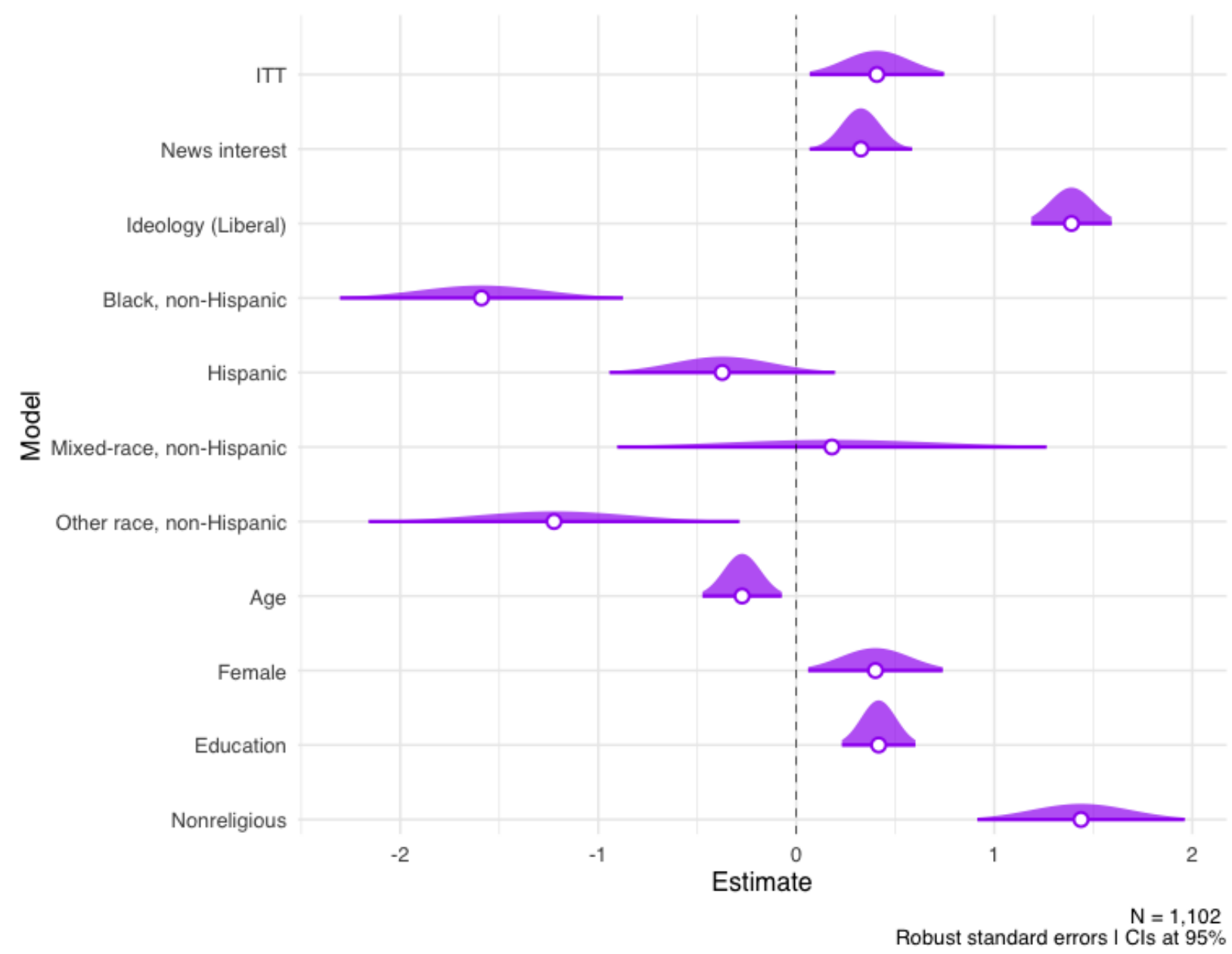

Notes: Points represent the marginal effect of each variable on support for same-sex marriage. Data are entropy weighted. Full model output presented in section B1 of the SI file.

among the wider public. Should my theoretical expectations hold true, we should expect the treatment to exhibit a positive and significant effect on the dependent measure in the direction of higher levels of support for same-sex marriage (H1). As hypothesized, the results indicate that those quasi-randomly assigned to the treatment group are more likely to support same-sex marriage than those in the control group. Given my use of a logit estimator, Figure 2 graphs the size of exponentiated coefficent for each variable. As indicated by Figure 1, the treatment is a positive and significant predictor of support for same-sex marriage $(p<.01)$. 
To obtain local average treatment effect (LATE) estimates, I also estimate the difference in the pre and post-treatment probabilities that a respondent will support same sex marriage. A respondent "as if" randomly assigned to the pre-shooting condition has a 42 predicted probability of supporting same-sex marriage. By contrast, a respondent "as if" randomly assigned to the post-shooting condition has a .52 predicted probability of supporting same-sex marriage. Quasi-random exposure to treatment is therefore associated with a 10-point increase in the predicted probability of a respondent supporting same sex marriage $($ LATE $=.010, p<.01)$.

\subsection{Subgroup Analyses: Ideology and Race}

Given this significant increase in support for same-sex marriage among the wider public post-shooting, might we expect to observe similar reactions to event exposure when individuals are contrasted on ideology (H2)? Figure 3 tests this possibility. The graph depicts the results of a model which includes a multiplicate interation term between the treatment and a binned variable for ideology (conservative, moderate, liberal). As indicated by Figure 3, support for same-sex marriage increased irrespective of political ideology.

Despite this general trend, the magnitude of the increase in support for same-sex marriage nonetheless varies across ideology. For instance, a conservative respondent "as if" randomly assigned to the pre-shooting condition has just a .20 predicted probability of supporting same. By contrast, a conservative respondent "as if" randomly assigned to the post-shooting condition has a .25 predicted probability of supporting same-sex marriage. Elsewhere, a moderate respondent quasi-randomly assigned to the pre-shooting condition a .44 predicted probability of supporting same-sex marriage. Conversely, a moderate respondent quasi-randomly assigned to the post-shooting condition has a .54 predicted probability of supporting same sex marriage. Lastly, a liberal respondent "as if" randomly assigned to the pre-shooting condition already has a .72 predicted probability of supporting same-sex marriage. Contrarily, a liberal respondent "as if" randomly as- 
Figure 3: Local Average Treatment Effects, by Ideology

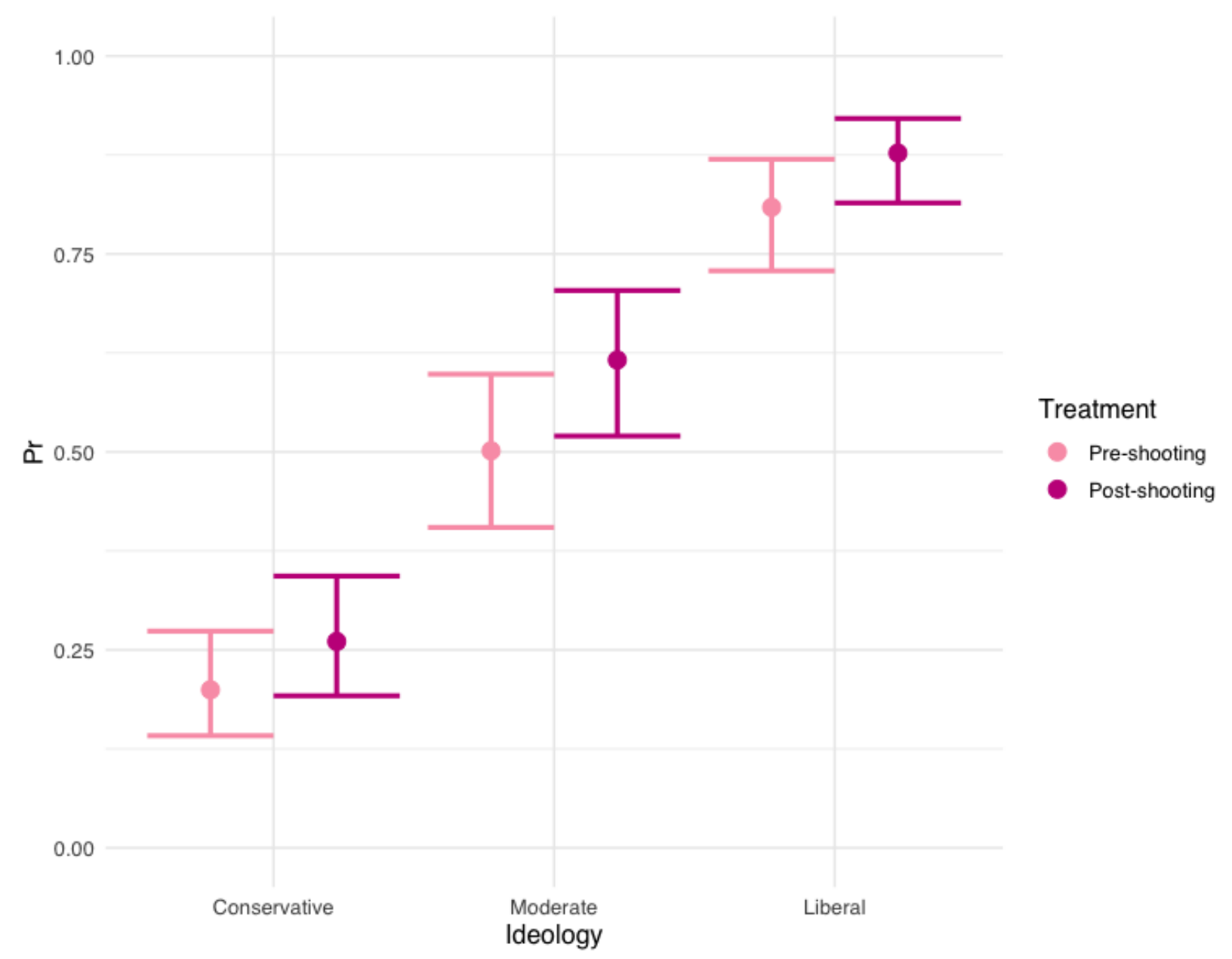

Notes: Points represent the pre-and post-treatment predicted levels of support for same-sex marriage, by ideology. The capped lines are 95 percent confidence intervals. Full model output presented in section B2 of the SI file.

signed to the post-shooting condition has a .80 predicted probability of supporting samesex marriage. Consequently, quasi-random exposure to news about Pulse is associated with an increased probability of supporting same sex marriage of 5 points for conservatives (LATE $=.05, p=$ n.s.), 10 points for moderates (LATE $=.05, p<.05$ ), and 8 points for liberals $($ LATE $=.05, p<.05)$

Finally, I also test for the possibility of asymmetric responses to the treatment when individuals are contrasted on race (H3). To test this possibility, Figure 4 presents the results of a model which includes a multiplicate interaction term between the treatment and 
the categorical measure for race. Comparing support for same-sex marriage among nonHispanic White respondents in the pre-and-post shooting conditions indicates some substantive differences. A non-Hispanic White respondent "as if" randomly assigned to the pre-shooting condition has a .47 predicted probability of supporting same-sex marriage. Conversely, a non-Hispanic respondent "as if" randomly assigned to the post-shooting condition has a .55 predicted probability of supporting same sex marriage. Therefore, quasi-random exposure to news about Pulse is associated with an 8-point increase in the predicted probability of a non-Hispanic White respondent supporting same-sex marriage $($ LATE $=.08, p<.01)$.

Relative to non-Hispanic Whites, non-Hispanic Blacks quasi-randomly assigned to the post-shooting condition likewise have a greater predicted probability of supporting same-sex marriage than non-Hispanic Blacks in the pre-shooting condition. However, the magnitude of this increase in support for same-sex marriage is not statistically distinguishable from zero. This pattern of insignificance holds for Hispanics, non-Hispanic mixed-race respondents, and non-Hispanic respondents who identify as another race. Though, as indicated by the quite large confidence intervals, these insignificant results may be a function of the relatively small cell sizes in each interaction.

\subsection{Robustness Tests}

To provide further weight to my key hypothesis that support for same-sex marriage increased after quasi-random exposure to news about Pulse, I now present a series of robustness tests. In my first robustness test, I demonstrate that the treatment has no effect on public support for a variety of measures that are unrelated to LGBT rights. Section $\mathrm{C} 1$ of the SI file contains the results of a series of models estimating the effects of the treatment on public support for increasing income taxes on the wealthy, Common Core standards for schools, a pathway to citizenship for illegal immigrants, a woman's right to an abortion, building the Keystone XL pipeline, ACA repeal, and federal regulation of 
Figure 4: Local Average Treatment Effects, by Race

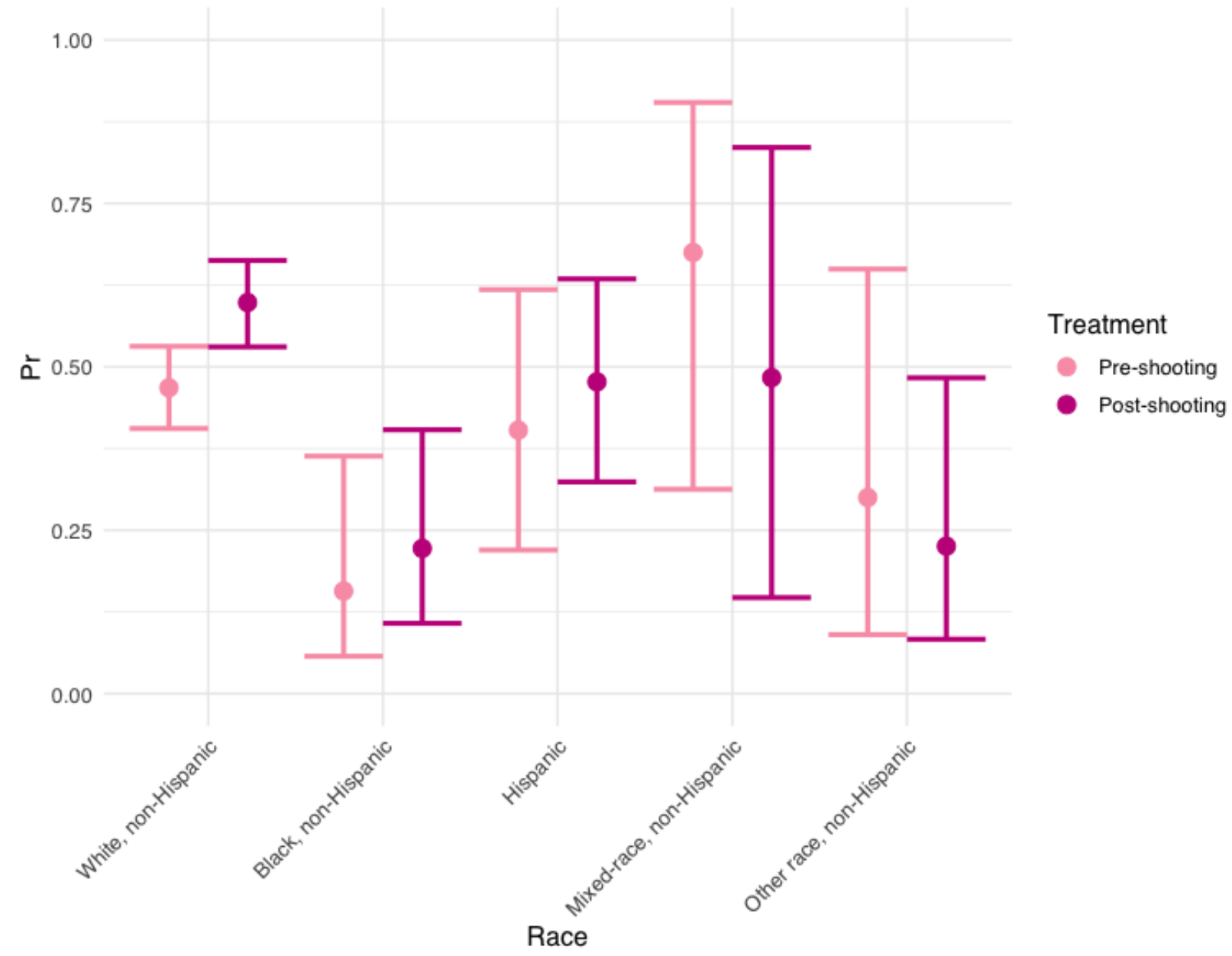

Notes: Points represent the pre-and post-treatment predicted levels of support for same-sex marriage, by race. The capped lines are 95 percent confidence intervals. Full model output presented in section B2 of the SI file.

$\mathrm{CO} 2$ emissions. Should the treatment shape support for same-sex marriage in particular, then we should expect to observe a pattern of insignificant results across these placebo models. The results of the placebo models indicate that the treatment has no significant effect on public support for any of these additional measures. Therefore, we can be reasonably confident that the treatment is driving public support for same-sex marriage in particular and not a broader set of policies.

Next, the exclusion restriction requires that the timing of the survey fieldwork for Wave 55 of TAPS only affects the dependent measure through exposure to news about 
Pulse (Muñoz et al. 2020). The most potent threat undercutting this assumption is that the results I have presented here are the result of pre-existing time trends. To satisfy the exclusion restriction, I utilize a regression discontinuity design (RDD) to demonstrate that public support for same-sex marriage was not increasing before the shooting on June 12. As indicated here (see section C2 of the SI file), there is little evidence of a pre-shooting increase in support for same sex-marriage, but a noteworthy increase in support after the shooting occurred. To further satisfy the exclusion restriction, I conduct a falsification test that assesses for the presence of a significant effect where one ought not to exist. Following the recommendation of Muñoz et al. (2020), I take the median survey finish time of the control group sample as the placebo cutoff (June 9, 19:59). Section C3 of the SI file contains the results of an additional model where support for same-sex marriage is modelled as a function of the placebo cutoff treatment. As indicated here, using the empirical median of the control group subsample as the cut-off time does not produce significant results.

Lastly, the one-sided non-compliance problem concerns whether those "as if" randomly assigned to the post-shooting condition have actually absorbed the treatment (Muñoz et al. 2020). Since respondent awareness of the Pulse shooting is not directly testable using the available data, I conduct a pseudo manipulation check by assessing issue salience. Salient events often have an impact on the types of problems that respondents consider to be the most important issues. If this is the case here, then we should expect to observe a noteworthy increase in the salience attributed to the issues to which the event is related. Fortunately, TAPS contains a categorical item asking respondents what issue they consider to be the most important facing the country. In my pseudo manipulation check, I test whether there is a post-shooting increase in the salience of "moral decline" as the most important issue facing the US. ${ }^{6}$ In section C4 of the SI file, I demonstrate that quasi-random exposure to the post-shooting condition is associated with an increase

\footnotetext{
${ }^{6}$ If Pulse increased public support for same-sex marriage, then we are likely to see opponents of samesex marriage (e.g., Christian conservatives) think that moral decline is an especially pressing issue.
} 
in the issue salience of moral decline. These results demonstrate a perceptible increase in the salience attributed to the arguments (e.g., moral decline) around which same-sex marriage are related.

\section{Discussion}

The extant scholarship finds mixed evidence in favor of the hypothesis that mass shootings lead to greater public support for gun control (Rogowski \& Tucker 2019). But are they able to shape public support for policies beyond gun control? In this research note, I have assessed whether "as if" random exposure to news about the June 2016 shooting at the Pulse nightclub, in Orlando, FL, led to increased support for same-sex marriage. Leveraging data from Wave 55 of The American Panel Survey (TAPS) and using a novel research design for event studies Muñoz et al. (2020), I find that TAPS respondents "as if" randomly assigned assigned to the post-shooting condition are on average 10 points more likely to support for same-sex marriage than those "as if" randomly assigned to the pre-shooting condition. Crucially, these results are robust to an exhaustive series of robustness checks. Even if mass shootings are not able to shape increased support for gun control, exposure to news about these tragic events may nonetheless shape support for policies that are related to the victim characteristics of mass shootings. 


\section{Bibliography}

Aisch, G., Buchanan, L., Burgess, J., Fessenden, F., Keller, J., Lai, K. R., Mykhyalshyn, I., Park, H., Pearce, A., Parshina-Kottas, Y., Pecanha, S., Singhvi, A., Watkins, D. \& Yourish, K. (2016), 'What happened inside the orlando nightclub', The New York Times . URL: $\quad$ https://www.nytimes.com/interactive/2016/06/12/us/what-happened-at-the-orlandonightclub-shooting.html

Flores, A. R. \& Barclay, S. (2016), 'Backlash, consensus, legitimacy, or polarization: The effect of same-sex marriage policy on mass attitudes', Political Research Quarterly 69(1), 43-56.

Hainmueller, J. (2012), ‘Entropy balancing for causal effects: A multivariate reweighting method to produce balanced samples in observational studies', Political Analysis 20(1), 25-46.

Kane, J. K. \& Barabas, J. (2019), 'No harm in checking: Using factual manipulation checks to assess attentiveness in experiments', American Journal of Political Science 63(1), 234249.

Kazyak, E. \& Stange, M. (2018), Journal of Homosexuality 65(14), 2028-2052.

Lee, H.-Y. \& Mutz, D. C. (2019), ‘Changing attitudes toward same-sex marriage: A threewave panel study', Political Behavior 41(3), 701-722.

Madigan, N., Mueller, B. \& Stolberg, S. G. (2016), ‘49 lives to horror in orlando: Mostly young, gay, and latino', The New York Times .

URL: https://www.nytimes.com/2016/06/14/us/orlando-shooting-victims-updates.html

Mason, L. (2015), “'i disrespectfully agree”: The differential effects of partisan sorting on social and issue polarization', American Journal of Political Science 59(1), 128-145. 
Mellon, J. (2014), 'Internet search data and issue salience: The properties of google trends as a measure of issue salience', Journal of Elections, Public Opinion, and Parties 24(1), 4572.

Muñoz, J., Falcó-Gimeno, A. \& Hernández, E. (2020), 'Unexpected event during survey design: Promise and pitfalls for causal inference', Political Analysis 28(2), 186-206.

Newman, B. J. \& Hartman, T. K. (2019), 'Mass shootings and public support for gun control', British Journal of Political Science 49(3), 1527-1553.

Olson, L. R., Cadge, W. \& Harrison, J. T. (2006), 'Religion and public opinion about samesex marriage', Social Science Quarterly 87(2), 340-360.

Page, B. I. \& Shaprio, R. Y. (2010), The rational public: Fifty years of trends in Americans' policy preferences, University of Chicago Press, Chicago, IL.

Rogowski, J. C. \& Tucker, P. D. (2019), 'Critical events and attitude change: Support for gun control after mass shootings', Political Science and Research Methods 7(4), 903-911. 


\section{Supplemental Information}

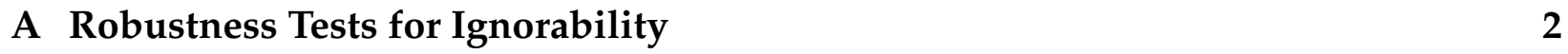

A.1 Alternate Bandwidths. . . . . . . . . . . . . . . . . . . . . . . . . 3

A.2 Balance Analysis . . . . . . . . . . . . . . . . . . . . . 6

A.3 Entropy Balancing for Covariate Adjustment $\ldots \ldots \ldots \ldots$. . . . . . . . 7

\begin{tabular}{lr}
\hline B Primary Regression Outputs & 8
\end{tabular}

B.1 ITT Estimates (Additive Effects) $\ldots \ldots \ldots$. . . . . . . . . . . . . . . . . . . 9

B.2 ITT Estimates (Interaction Effects for Ideology) $\ldots \ldots \ldots$. . . . . . . . . 10

B.3 ITT Estimates (Interaction Effects for Race) $\ldots \ldots \ldots \ldots \ldots$

\begin{tabular}{ll}
\hline C Robustness Tests for Excludability and Compliance & 12
\end{tabular}

C.1 Placebo tests . . . . . . . . . . . . . . . . . . . . . . . . 13

C.2 Inspection of Pre-Existing Time Trends . . . . . . . . . . . . . . . . . 14

C.3 Falsification Tests . . . . . . . . . . . . . . . . . . . . . . . . . . . . . . 15

C.4 Pseudo Manipulation Checks . . . . . . . . . . . . . . . . . . . 16 
A Robustness Tests for Ignorability 


\section{A.1 Alternate Bandwidths}

Table 1: ITT Estimates Halving Post-Event Exposure Time (Additive Effects)

\begin{tabular}{lc}
\hline & Support for ssm \\
\hline ITT & $.246^{* *}$ \\
& $(.084)$ \\
News interest & $.217^{*}$ \\
& $(.105)$ \\
Ideology (Liberal) & $1.411^{* * *}$ \\
& $(.107)$ \\
Black, non-Hispanic & $-.403^{* * *}$ \\
& $(.091)$ \\
Hispanic & -.103 \\
& $(.079)$ \\
Mixed race, non-Hispanic & .064 \\
& $(.070)$ \\
Other race, non-Hispanic & $.254^{*}$ \\
& $(.111)$ \\
Age & $-.268^{* *}$ \\
& $(.098)$ \\
Female & $.212^{*}$ \\
& $(.088)$ \\
Education & $.362^{* * *}$ \\
& $(.093)$ \\
Nonreligious & $.580^{* * *}$ \\
& $(.103)$ \\
\hline Constant & -.145 \\
& $(.084)$ \\
\hline Pseudo & .309 \\
Log likelihood & -335.52379 \\
$\mathrm{~N}$ & 1,010 \\
\hline Nots: Talo
\end{tabular}

Notes: Table entries are logit coefficients. Robust standard errors given in parentheses. Data are entropy weighted. ${ }^{*} p<.05{ }^{* *} p<.01{ }^{* * *} p<.001$. 
Table 2: ITT Estimates Halving Post-Event Exposure Time (Interactive Effects for Ideology)

\begin{tabular}{|c|c|}
\hline & Support for ssm \\
\hline \multicolumn{2}{|l|}{ ITT $x$ ideology } \\
\hline Conservative & $\begin{array}{l}-.118 \\
(.112)\end{array}$ \\
\hline Moderate & $\begin{array}{c}.238 \\
(.133)\end{array}$ \\
\hline Liberal & $\begin{array}{c}.508^{* * *} \\
(.130)\end{array}$ \\
\hline News interest & $\begin{array}{l}.230^{* *} \\
(.088)\end{array}$ \\
\hline Black, non-Hispanic & $\begin{array}{c}-.213^{* *} \\
(.072)\end{array}$ \\
\hline Hispanic & $\begin{array}{l}-.028 \\
(.077)\end{array}$ \\
\hline Mixed-race, non-Hispanic & $\begin{array}{c}.052 \\
(.070)\end{array}$ \\
\hline Other race, non-Hispanic & $\begin{array}{l}-.212^{*} \\
(.086)\end{array}$ \\
\hline Age & $\begin{array}{l}-.208^{*} \\
(.084)\end{array}$ \\
\hline Female & $\begin{array}{l}.334^{* * *} \\
(.077)\end{array}$ \\
\hline Education & $\begin{array}{c}.350^{* * *} \\
(.080)\end{array}$ \\
\hline Nonreligious & $\begin{array}{c}.770^{* * *} \\
(.085)\end{array}$ \\
\hline Constant & $\begin{array}{l}-.072 \\
(.072)\end{array}$ \\
\hline Pseudo & .141 \\
\hline Log likelihood & -441.97962 \\
\hline $\mathrm{N}$ & 1,010 \\
\hline
\end{tabular}


Table 3: ITT Estimates Halving Post-Event Exposure Time (Interactive Effects for Race)

\begin{tabular}{lc}
\hline & Support for ssm \\
\hline ITT x race & $.340^{* * *}$ \\
White, non-Hispanic & $.091)$ \\
& -.034 \\
Black, non-Hispanic & $.307)$ \\
& .127 \\
Hispanic & $(.244)$ \\
& .166 \\
Mixed-race, non-Hispanic & $(.499)$ \\
& -.444 \\
Other race, non-Hispanic & $(.455)$ \\
& $.236^{*}$ \\
News interest & $(.103)$ \\
& $1.300^{* * *}$ \\
Ideology (Liberal) & $(.105)$ \\
& $-.220^{*}$ \\
Age & $(.092)$ \\
& $.231^{* *}$ \\
Female & $(.086)$ \\
& $.378^{* * *}$ \\
Education & $(.092)$ \\
& $.600^{* * *}$ \\
Nonreligious & $(.099)$ \\
\hline Constant & $-.190^{*}$ \\
& $(.083)$ \\
\hline Pseudo & .284 \\
Log likelihood & -.368 .48998 \\
\hline & 1,010 \\
\hline
\end{tabular}

Notes: Table entries are logit coefficients. Robust standard errors given in parentheses. Data are entropy weighted. ${ }^{*} p<.05^{* *} p<.01{ }^{* * *} p<.001$. 


\section{A.2 Balance Analysis}

Table 4: Covariate Difference Between Treatment and Control Groups

\begin{tabular}{lccc}
\hline & Pre-shooting & Post-shooting & $p$ \\
\hline News interest & 5.954 & 5.789 & $* * *$ \\
Ideology (Liberal) & 3.680 & 3.878 & n.s. \\
Black, non-Hispanic & $10.3 \%$ & $8.2 \%$ & $* *$ \\
Hispanic & $9.5 \%$ & $17.5 \%$ & $*$ \\
Mixed race, non-Hispanic & $.4 \%$ & $2.6 \%$ & n.s. \\
Other race, non-Hispanic & $4.1 \%$ & $6.4 \%$ & n.s. \\
Age & 53.542 years & 47.283 years & $* * *$ \\
Female & $48.6 \%$ & $49.5 \%$ & $* * *$ \\
Education & 2.930 & 2.824 & n.s. \\
Nonreligious & $18.5 \%$ & $24.6 \%$ & n.s. \\
\hline
\end{tabular}

Notes: Data are weighted using TAPS poststratification weight (internet adjusted). Asterisks indicate a statistically significant mean difference between treatment and control groups $\left({ }^{*} p<.05^{* *} p<.01^{* * *} p<.001\right)$. 


\title{
A.3 Entropy Balancing for Covariate Adjustment
}

\author{
Table 5: Before Weighting
}

\begin{tabular}{lcccccc}
\hline & Mean & $\begin{array}{c}\text { Treatment } \\
\text { variance }\end{array}$ & Skewness & Mean & $\begin{array}{c}\text { Control } \\
\text { variance }\end{array}$ & Skewness \\
\hline News interest & 6.017 & 2.171 & -1.702 & 6.387 & 1.319 & -2.658 \\
Ideology (liberal) & 3.88 & 2.778 & .065 & 3.769 & 2.903 & .117 \\
Black, non-Hispanic & $8.9 \%$ & .081 & 2.781 & $4.9 \%$ & .047 & 4.133 \\
Hispanic & $12.1 \%$ & .107 & 2.313 & $6.8 \%$ & .064 & 3.412 \\
Mixed race, non-Hispanic & $2.1 \%$ & .020 & 6.62 & $1.5 \%$ & .015 & 7.818 \\
Other race, non-Hispanic & $5.3 \%$ & .050 & 3.972 & .037 & .036 & 4.873 \\
Age & 54.04 years & 255.1 & -.033 & 60.47 years & 203.9 & -.540 \\
Female & $56.6 \%$ & .246 & -.267 & $56.5 \%$ & .246 & -.265 \\
Education & 3.308 & .680 & -.920 & 3.308 & .672 & -.923 \\
Nonreligious & $17.7 \%$ & .146 & 1.689 & $18.4 \%$ & .150 & 1.63 \\
\hline
\end{tabular}

Table 6: After Weighting

\begin{tabular}{lcccccc}
\hline & Mean & $\begin{array}{c}\text { Treatment } \\
\text { variance }\end{array}$ & Skewness & Mean & $\begin{array}{c}\text { Control } \\
\text { variance }\end{array}$ & Skewness \\
\hline News interest & 6.017 & 2.171 & -1.702 & 6.018 & 2.2 & -1.898 \\
Ideology (liberal) & 3.88 & 2.778 & .065 & 3.88 & 2.709 & .031 \\
Black, non-Hispanic & $8.9 \%$ & .081 & 2.861 & $8.9 \%$ & .081 & 2.873 \\
Hispanic & $12.1 \%$ & .107 & 2.313 & $1.21 \%$ & .107 & 2.315 \\
Mixed race, non-Hispanic & $2.1 \%$ & .020 & 6.62 & $2.1 \%$ & .020 & 6.625 \\
Other race, non-Hispanic & $5.3 \%$ & .050 & 3.972 & $5.3 \%$ & .050 & 3.974 \\
Age & 54.04 years & 255.1 & -.033 & 54.06 years & 235.9 & -.240 \\
Female & $56.6 \%$ & .246 & -.267 & $56.5 \%$ & .246 & -.265 \\
Education & 3.308 & .680 & -.920 & 3.308 & .672 & -.923 \\
Nonreligious & $17.7 \%$ & .146 & 1.689 & $17.7 \%$ & .146 & 1.689 \\
\hline
\end{tabular}


B Primary Regression Outputs 


\section{B.1 ITT Estimates (Additive Effects)}

Table 7: ITT Estimates for Support fot Same-Sex Marriage

\begin{tabular}{lc}
\hline & Support for ssm \\
\hline ITT & $.201^{* *}$ \\
& $(.083)$ \\
News interest & $.286^{*}$ \\
& $(.111)$ \\
Ideology (liberal) & $1.413^{* * *}$ \\
& $(.103)$ \\
Black, non-Hispanic & $-.400^{* * *}$ \\
& $(.089)$ \\
Hispanic & -.107 \\
& $(.080)$ \\
Mixed race, non-Hispanic & .023 \\
& $(.067)$ \\
Other race, non-Hispanic & $-.253^{* *}$ \\
& $(.095)$ \\
Age & $-.268^{* *}$ \\
& $(.098)$ \\
Female & $.199^{*}$ \\
Education & $(.084)$ \\
Nonreligious & $.403^{* * *}$ \\
\hline Constant & $(.089)$ \\
& $.547^{* * *}$ \\
Pseudo & $(.097)$ \\
\hline Nog pseudolikelihood & -.157 \\
& $(.080)$ \\
\hline & .310 \\
& -44.86903 \\
& 1,103 \\
\hline
\end{tabular}

Notes: Table entries are logit coefficients. Robust standard errors given in parentheses. Data are entropy weighted. ${ }^{*} p<.05^{* *} p<.01^{* * *} p<.001$. 


\section{B.2 ITT Estimates (Interaction Effects for Ideology)}

Table 8: ITT Estimates (Interactive Effects for Ideology)

\begin{tabular}{|c|c|}
\hline & Support for ssm \\
\hline \multicolumn{2}{|l|}{ ITT $x$ ideology } \\
\hline Conservative & $\begin{array}{l}-.076 \\
(.107)\end{array}$ \\
\hline Moderate & $\begin{array}{c}.217 \\
(.130)\end{array}$ \\
\hline Liberal & $\begin{array}{l}.341^{* *} \\
(.130)\end{array}$ \\
\hline News interest & $\begin{array}{l}.246^{* *} \\
(.088)\end{array}$ \\
\hline Black, non-Hispanic & $\begin{array}{c}-.199 * * \\
(.068)\end{array}$ \\
\hline Hispanic & $\begin{array}{l}-.015 \\
(.077)\end{array}$ \\
\hline Mixed-race, non-Hispanic & $\begin{array}{c}.038 \\
(.063)\end{array}$ \\
\hline Other race, non-Hispanic & $\begin{array}{c}-.225^{* *} \\
(.079)\end{array}$ \\
\hline Age & $\begin{array}{l}-.187^{*} \\
(.083)\end{array}$ \\
\hline Female & $\begin{array}{l}.325^{* * *} \\
(.074)\end{array}$ \\
\hline Education & $\begin{array}{l}.383^{* * *} \\
(.077)\end{array}$ \\
\hline Nonreligious & $\begin{array}{l}.749^{* * *} \\
(.080)\end{array}$ \\
\hline Constant & $\begin{array}{l}-.111 \\
(.069)\end{array}$ \\
\hline Pseudo & .137 \\
\hline Log likelihood & -554.88971 \\
\hline $\mathrm{N}$ & 1,103 \\
\hline
\end{tabular}

Notes: Table entries are logit coefficients. Robust standard errors given in parentheses. Data are entropy weighted. ${ }^{*} p<.05^{* *} p<.01^{* * *} p<.001$. 


\section{B.3 ITT Estimates (Interaction Effects for Race)}

Table 9: ITT Estimates (Interaction Effects for Race)

\begin{tabular}{lc}
\hline & Support for ssm \\
\hline ITT x race & $.284^{* * *}$ \\
White, non-Hispanic & $(.090)$ \\
& -.037 \\
Black, non-Hispanic & $(.313)$ \\
& .134 \\
Hispanic & $(.250)$ \\
& -.263 \\
Mixed-race, non-Hispanic & $(.494)$ \\
& -.329 \\
Other race, non-Hispanic & $(.384)$ \\
& $.301^{* *}$ \\
News interest & $(.109)$ \\
& $1.310^{* * *}$ \\
Ideology (Liberal) & $(.100)$ \\
& $-.223^{*}$ \\
Age & $(.092)$ \\
& .216 \\
Female & $(.083)$ \\
Education & $.397^{* * *}$ \\
Nonreligious & $(.090)$ \\
\hline Constant & $.563^{* * *}$ \\
Pseudo & $(.094)$ \\
\hline Nog likelihood & $-.200^{*}$ \\
& $(.080)$ \\
\hline
\end{tabular}

Notes: Table entries are logit coefficients. Robust standard errors given in parentheses. Data are entropy weighted. ${ }^{*} p<.05^{* *} p<.01^{* * *} p<.001$. 
C Robustness Tests for Excludability and Compliance 


\section{C.1 Placebo tests}

Table 10: ITT Estimates for Placebo Models

\begin{tabular}{|c|c|c|c|c|c|c|c|}
\hline & $\begin{array}{l}\text { Increase income } \\
\text { taxes on the } \\
\text { wealthy }\end{array}$ & $\begin{array}{l}\text { Common core } \\
\text { standards for } \\
\text { schools }\end{array}$ & $\begin{array}{l}\text { Pathway to } \\
\text { citizenship } \\
\text { for illegal } \\
\text { immigrants }\end{array}$ & $\begin{array}{l}\text { Woman's } \\
\text { right to } \\
\text { have an } \\
\text { abortion }\end{array}$ & $\begin{array}{l}\text { Building } \\
\text { Keystone XL } \\
\text { pipeline }\end{array}$ & ACA repeal & $\begin{array}{l}\text { Federal } \\
\text { regulation } \\
\text { of } \mathrm{CO} 2 \\
\text { emissions }\end{array}$ \\
\hline \multirow{2}{*}{ ITT } & -.047 & .053 & -.050 & .144 & .072 & -.106 & .024 \\
\hline & $(.079)$ & $(.071)$ & $(.072)$ & $(.080)$ & $(.076)$ & $(.276)$ & $(.077)$ \\
\hline \multirow{2}{*}{ News interest } & $.188^{*}$ & .112 & $.234^{* *}$ & $.310^{* *}$ & $.227^{*}$ & .037 & $.292^{* *}$ \\
\hline & $(.092)$ & $(.082)$ & $(.089)$ & $(.092)$ & $(.100)$ & $(.088)$ & $(.091)$ \\
\hline \multirow{2}{*}{ Ideology (Liberal) } & $1.129^{* * *}$ & $.377^{* * *}$ & $.734^{* * *}$ & $1.245^{* * *}$ & $-1.018^{* * *}$ & $-1.202^{* * *}$ & $1.232^{* * *}$ \\
\hline & $(.099)$ & $(.079)$ & $(.084)$ & $(.104)$ & $(.096)$ & $(.104)$ & $(.010)$ \\
\hline \multirow{2}{*}{ Black, non-Hispanic } & .129 & $.158^{*}$ & .069 & .010 & $-.213^{*}$ & $-.283^{* *}$ & -.082 \\
\hline & $(.092)$ & $(.070)$ & $(.076)$ & $(.065)$ & $(.095)$ & $(.091)$ & $(.088)$ \\
\hline \multirow{2}{*}{ Hispanic } & $.203^{*}$ & .113 & $.215^{* *}$ & -.119 & $-.168^{*}$ & $-.235^{* *}$ & .016 \\
\hline & $(.094)$ & $(.067)$ & $(.080)$ & $(.080)$ & $(.080)$ & $(.080)$ & $(.076)$ \\
\hline \multirow{2}{*}{ Mixed race, non-Hispanic } & .015 & -.072 & -.017 & .101 & -.037 & .030 & -.027 \\
\hline & $(.068)$ & $(.078)$ & $(.066)$ & $(.076)$ & $(.078)$ & $(.065)$ & $(.060)$ \\
\hline \multirow{2}{*}{ Other race, non-Hispanic } & .051 & .094 & -.107 & -.119 & -.060 & -.090 & -.050 \\
\hline & $(.077)$ & $(.065)$ & $(.069)$ & $(.072)$ & $(.073)$ & $(.082)$ & $(.071)$ \\
\hline \multirow{2}{*}{ Age } & .125 & .078 & .003 & $.281^{* * *}$ & $.182^{*}$ & -.133 & -.042 \\
\hline & $(.088)$ & $(.083)$ & $(.081)$ & $(.098)$ & $(.085)$ & $(.091)$ & $(.085)$ \\
\hline \multirow{2}{*}{ Female } & $.185^{*}$ & -.079 & .125 & -.061 & $-.520^{* * *}$ & -.103 & .012 \\
\hline & $(.080)$ & $(.072)$ & $(.073)$ & $(.083)$ & $(.081)$ & $(.080)$ & $(.079)$ \\
\hline \multirow{2}{*}{ Education } & -.146 & .046 & $.356^{* * *}$ & $.234^{* *}$ & -.030 & $-.196^{*}$ & $.264^{* *}$ \\
\hline & $(.086)$ & $(.078)$ & $(.075)$ & $(.079)$ & $(.083)$ & $(.087)$ & $(.079)$ \\
\hline \multirow{2}{*}{ Nonreligious } & .035 & -.089 & $.177^{*}$ & $.498^{* * *}$ & $-.323^{* * *}$ & $-.208^{*}$ & .087 \\
\hline & $(.102)$ & $(.074)$ & $(.078)$ & $(.111)$ & $(.087)$ & $(.089)$ & $(.084)$ \\
\hline \multirow{2}{*}{ Constant } & $.853^{* * *}$ & $-.804^{* * *}$ & .025 & $.757^{* * *}$ & $-.553^{* * *}$ & $-.204^{* *}$ & $.439 * * *$ \\
\hline & $(.079)$ & $(.070)$ & $(.068)$ & $(.086)$ & $(.075)$ & $(.073)$ & $(.073)$ \\
\hline Pseudo & .184 & .038 & .144 & .254 & .234 & .226 & .212 \\
\hline Log likelihood & -485.56747 & -.561 .21948 & -551.96582 & -465.16527 & -.468 .68847 & -495.46315 & -498.33542 \\
\hline $\mathrm{N}$ & 1,104 & 1,107 & 1,105 & 1,110 & 1,104 & 1,105 & 1,102 \\
\hline
\end{tabular}

Notes: Table entries are logit coefficients. Robust standard errors given in parentheses. Data are entropy weighted. ${ }^{*} p<.05^{* *} p<.01{ }^{* * *} p<.001$. 


\section{C.2 Inspection of Pre-Existing Time Trends}

Figure 5: Regression Discontinuity Model

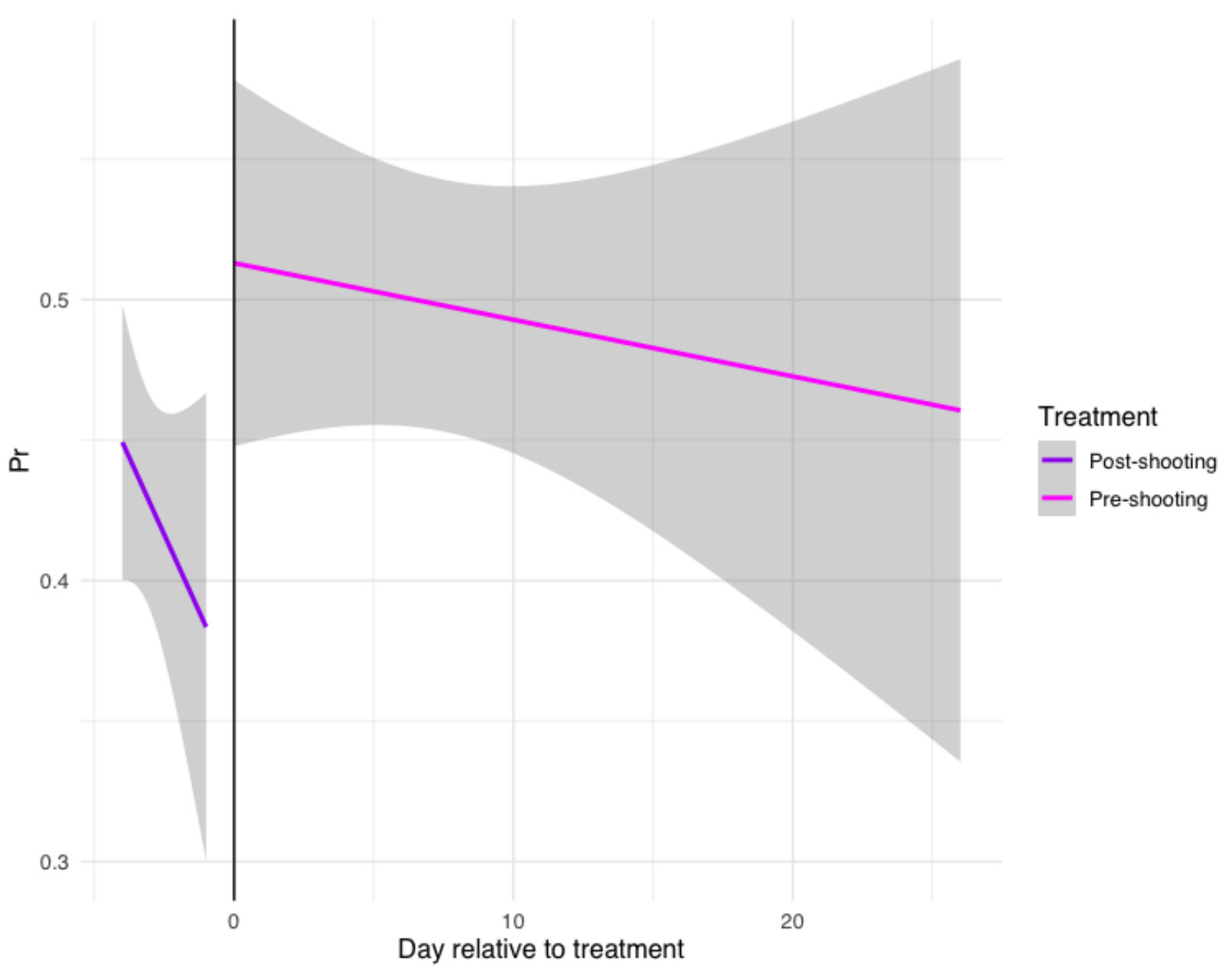




\section{C.3 Falsification Tests}

Table 11: ITT Estimates (Median Interview Date as Placebo Cutoff)

\begin{tabular}{lc}
\hline & Support for ssm \\
\hline ITT & .077 \\
News interest & $.082)$ \\
& $.257^{*}$ \\
Ideology (liberal) & $(.121)$ \\
& $1.401^{* * *}$ \\
Black, non-Hispanic & $(.104)$ \\
& $-.373^{* * *}$ \\
Hispanic & $(.093)$ \\
& -.062 \\
Mixed-race, non-Hispanic & $(.087)$ \\
& .058 \\
Other race, non-Hispanic & $(.065)$ \\
& $-.235^{*}$ \\
Age & $(.095)$ \\
Female & $.281^{* *}$ \\
& $(.102)$ \\
Education & $.219^{* *}$ \\
Nonreligious & $(.083)$ \\
& $.495^{* * *}$ \\
Constant & $(.015)$ \\
Pseudo & $504^{* * *}$ \\
& $(.096)$ \\
\hline Nog likelihood & $-.183^{*}$ \\
& $(.078)$ \\
\hline & .309 \\
& -665.10466 \\
& 1,103 \\
\hline
\end{tabular}

Notes: Table entries are logit coefficients. Robust standard errors given in parentheses. Data are entropy weighted. ${ }^{*} p<.05^{* *} p<.01^{* * *} p<.001$. 


\section{C.4 Pseudo Manipulation Checks}

Table 12: ITT Estimates for Moral Decline

\begin{tabular}{|c|c|}
\hline & $\begin{array}{l}\text { Moral decline } \\
\text { most important } \\
\text { issue facing US }\end{array}$ \\
\hline ITT & $\begin{array}{l}.313^{* * *} \\
(.108)\end{array}$ \\
\hline News interest & $\begin{array}{l}.386^{*} \\
(.162)\end{array}$ \\
\hline Ideology (Liberal) & $\begin{array}{c}-.320^{* *} \\
(.115)\end{array}$ \\
\hline Black, non-Hispanic & $\begin{array}{l}-.163 \\
(.138)\end{array}$ \\
\hline Hispanic & $\begin{array}{l}-.099 \\
(.131)\end{array}$ \\
\hline Mixed race, non-Hispanic & $\begin{array}{l}.026 \\
(.087)\end{array}$ \\
\hline Other race, non-Hispanic & $\begin{array}{l}-.043 \\
(.119)\end{array}$ \\
\hline Age & $\begin{array}{l}.204 \\
(.115)\end{array}$ \\
\hline Female & $\begin{array}{l}.247^{*} \\
(.117)\end{array}$ \\
\hline Education & $\begin{array}{c}.052 \\
(.115)\end{array}$ \\
\hline Nonreligious & $\begin{array}{l}-.302 \\
(.168)\end{array}$ \\
\hline Constant & $\begin{array}{c}-2.506^{* * *} \\
(.124)\end{array}$ \\
\hline Pseudo & .075 \\
\hline Log likelihood & -262.9395 \\
\hline $\mathrm{N}$ & 1,108 \\
\hline
\end{tabular}

Notes: Table entries are logit coefficients. Robust standard errors given in parentheses. Data are entropy weighted. ${ }^{*} p<.05^{* *} p<.01{ }^{* * *} p<.001$. 